\title{
Effects of fat and cinnamon feeding on adiponectin after rat injection with dexamethasone
}

\author{
Mahmoud Hassan El-Bidawy ${ }^{1,}$, , Nabil Mohamed Elbahey ${ }^{2}$, Mohamed Mahmoud Shaaban $^{3}$ \\ ${ }^{1}$ Department of Biomedical Sciences, Division of Physiology, College of Medicine, Salman bin Abdulaziz University, Al Kharj, Saudi \\ Arabia, Department of Medical Physiology, Faculty of Medicine, Cairo University, Egypt \\ ${ }^{2}$ Department of Biomedical Sciences, Division of Pharmacology, College of Medicine, Salman bin Abdulaziz University, Al Kharj, Saudi \\ Arabia \\ ${ }^{3}$ Department of Biomedical Sciences, Division of Histology, College of Medicine, Salman bin Abdulaziz University, Al Kharj, Saudi \\ Arabia
}

\section{Email address:}

melbidawy2005@hotmail.com (M. H. El-Bidawy)

\section{To cite this article:}

Mahmoud Hassan. El-Bidawy, Nabil Mohamed. Elbahey, Mohamed Mahmoud Shaaban. Effects of Fat and Cinnamon Feeding on Adiponectin after Rat Injection with Dexamethasone. Clinical Medicine Research. Vol. 2, No. 6, 2013, pp. 162-166.

doi: 10.11648/j.cmr.20130206.19

\begin{abstract}
Chronically excessive numbers of glucocorticoids are known to induce insulin resistance, which is possibly involved in impairing the insulin signaling in liver, muscle, and adipose tissues. Excessive levels of cortisol are characterized by the symptoms of abdominal obesity, hypertension, glucose intolerance or diabetes and dyslipidemia ,all of these features are shared by the condition of insulin resistance .Consumption of high levels of dietary fat is thought to be a major factor in the promotion of obesity and insulin resistance [7]. Fatty acid composition in the diet is another mechanism implicated in the development of insulin resistance [6]. Several environmental factors, including high-fat diet, are reported to activate the functioning of the hypothalamus-pituitary-adrenal axis [HPA]. Frequently evoked HPA-axis secretes excessive amount of cortisol [21] and elevated cortisol level is implicated in the development of entire spectrum of the metabolic syndrome, including insulin resistance, visceral obesity and dyslipidemia as well as the kinds of [21]. Cinnamon contains biologically active substances that have demonstrated insulin-mimetic properties. In vitro [3] and in vivo [1, 20] studies have shown that cinnamon enhances glucose uptake by activating insulin receptor kinase activity, autophosphorylation of the insulin receptor, and glycogen synthase activity. Other recent studies have demonstrated the ability of cinnamon to reduce lipid levels in fructose-fed rats, potentially via inhibiting hepatic 3-hydroxy-3-methylglutaryl CoA reductase activity [2]. Adiponectin is the most abundant plasma protein synthesized for the most part in adipose tissue, and it is an insulin-sensitive hormone,playing a central role in glucose and lipid metabolism [7] Furthermore, adiponectin levels are inversely associated with visceral adiposity [15]. Moreover, adiponectin has been reported to exhibit anti-atherosclerotic and anti-inflammatory effects $[17,16]$.
\end{abstract}

Keywords: Fat Feeding, Cinnamon Feeding, Adiponectin, Dexamethasone

\section{Introduction}

Adiponectin the most abundant plasma protein that is synthesized from differentiated adipocytes, has reduced plasma levels in clinical conditions associated with insulin resistance, including obesity, type 2 diabetes, dyslipidemia and hypertension $[18,11]$.

Several studies have demonstrated that adiponectin has a central role in glucose and lipid metabolism. Accordingly, the infusion of adiponectin in mice decreased the expression of hepatic gluconeogenesis enzymes, inhibited glucose production and increased the hepatic effect of insulin [6].

In addition to its effect on glucose levels, adiponectin improved insulin sensitivity by reducing the levels of free fatty acids in the plasma and by increasing their oxidation in the muscle, according to some authors $[5,6]$.

Few studies have investigated the effect of diet composition on the expression of adiponectin and its receptors. One such study showed that that a high calorie diet decreased serum adiponectin levels [16]. Bullen et al [5] showed that age and a high-fat diet, both of which predispose an organism to obesity and insulin resistance, 
reduced adiponectin and increased adipoR1 and adipoR2 levels.

An excess of cortisol, as seen in Cushing's syndrome or with clinical administration of glucocorticoids that is used to treat acute and chronic inflammatory diseases, leads to symptoms of abdominal obesity, hypertension, glucose intolerance or diabetes and dyslipidemia, all of which are also features of insulin resistance [8, 4].

Previous studies have shown that glucocorticoids inhibit adiponectin expression in vitro and in animal models $[9,13]$.

In rats, cinnamon potentiates insulin-regulated glucose utilization [3]. In patients with diabetes, cinnamon extracts have beneficial effects in reducing fasting plasma glucose, cholesterol and triglycerides [1] and [20]. In overweight patients [20] and [2] and women with the polycystic ovary syndrome [12], nutritional intakes of cinnamon also improve insulin sensitivity and lead to beneficial antioxidant effects.

\section{Materials and Methods}

\subsection{Animals}

Male Sprague-Dawley rats, weighing $250 \pm 10 \mathrm{~g}$. The animals were housed at $24 \pm 1{ }^{\circ} \mathrm{C}, 45 \pm 5 \%$ humidity and $12 \mathrm{~h}$ light-12 $\mathrm{h}$ dark cycle. They were left to acclimatize for 1 week before the experiments. The experimental procedures were carried out in accordance with international guidelines for care and use of laboratory animals.

\subsection{Drugs and Chemicals}

Dexamethasone $[\mathrm{DEX}]$ sodium phosphate powder and cholesterol powder were obtained from Sigma-Aldrich Company, USA. Commercial cinnamon powder was prepared as a water extract at a concentration of $60 \mathrm{~g} / 100 \mathrm{ml}$ distilled $\mathrm{H} 2 \mathrm{O} 2$

\subsection{Experimental Protocol}

The rats were randomly divided into four equal groups [n $=8$, each]. The first group [control group] was fed the standard laboratory chow and received daily intra-peritoneal injection [i.p] normal saline [vehicle of DEX] for 14 days. The second group animals were fed high-fat diet $[4 \%$

cholesterol diet, w/w] for 14 days. The rats of the third and fourth groups were fed high-fat diet [ $4 \%$ cholesterol diet, $\mathrm{w} / \mathrm{w}]$, and received a daily i.p. injection of dexamethasone for 14 days. The third and fourth group animals received a daily i.p. injection of normal saline [vehicle of cinnamon] or cinnamon water extract $[1 \mathrm{~g} / \mathrm{kg}]$, respectively, for 14 consecutive days.

\subsection{Sample Preparation and Biochemical Studies}

At the end of 2 weeks, the rats were sacrificed and blood samples were collected after $12 \mathrm{~h}$-fasting. A drop of blood was used to measure fasting blood glucose by the blood glucose meter [Accu-Chek, Roche Diagnostics, Germany]. A portion of blood was kept in EDTA tubes and used for determination of glycohemoglobin [HbA1C] level using a colorimetric assay kit [Stanbio Laboratory, USA]. The other portion of the blood samples were centrifuged for $10 \mathrm{~min}$ at $5000 \mathrm{rpm}$ to obtain clear sera. Subsequently, serum lipid profile [total cholesterol, HDL-C, and triglycerides] was assessed using colorimetric assay kits [Stanbio Laboratory, USA].

\subsection{Histopathological Examinations}

Parts of the isolated liver tissues obtained from each animal were fixed in $10 \%$ formalin solution, dehydrated in ascending grades of alcohol and embedded in paraffin. Sections of $4-\mu \mathrm{m}$ thickness were taken, stained with hematoxylin and eosin [H\&E] and examined by light microscopy by a pathologist unaware of the treatment protocol.

\subsection{Statistical Analysis}

Data are expressed as mean \pm S.E.M. Statistical evaluation was performed by one-way analysis of variance [ANOVA] followed by Turkey test for multiple comparisons. All analyses were performed with SPSS software package [version 18]. P $\square 0.05$ was selected as the criterion for statistical significance

\section{Result Analysis}

Table 1. Effects of cinnamon [CIN] treatment on fasting blood glucose, glycohemoglobin [HbA1C], and serum adiponectin and lipid profile in rats fed high-fat diet [HFD] and received dexamethasone [DEX] for 14 days

\begin{tabular}{|c|c|c|c|c|}
\hline Parameter Measured & Control & HFD & DEX + HFD & CIN + DEX + HFD \\
\hline Blood glucose $[\mathrm{mg} / \mathrm{dl}]$ & $74.62 \pm 5.85$ & $102.41 \pm 8.33$ & $147.58 \pm 12.91 \mathrm{a}, \mathrm{b}$ & $94.75 \pm 6.71 \mathrm{c}$ \\
\hline $\mathrm{HbA} 1 \mathrm{C}[\%]$ & $4.72 \pm 0.51$ & $5.68 \pm 0.38$ & $7.31 \pm 0.46 \mathrm{a}, \mathrm{b}$ & $5.01 \pm 0.27 \mathrm{c}$ \\
\hline Adiponectin [ng/ml] & $113.06 \pm 10.88$ & $72.43 \pm 5.82 \mathrm{a}$ & $28.64 \pm 3.57 \mathrm{a}, \mathrm{b}$ & $84.30 \pm 7.41 \mathrm{a}, \mathrm{c}$ \\
\hline Total Cholesterol [mg/dl] & $75.36 \pm 6.15$ & $104.84 \pm 7.35 \mathrm{a}$ & $137.69 \pm 5.44 \mathrm{a}, \mathrm{b}$ & $97.14 \pm 4.52 \mathrm{c}$ \\
\hline HDL-C [mg/dl] & $34.86 \pm 2.19$ & $21.64 \pm 1.52 \mathrm{a}$ & $18.49 \pm 2.36 \mathrm{a}$ & $31.37 \pm 1.99 \mathrm{c}$ \\
\hline Triglycerides [mg/dl] & $90.18 \pm 7.51$ & $101.32 \pm 8.92$ & $94.24 \pm 7.45$ & $85.17 \pm 5.26$ \\
\hline
\end{tabular}

All the values are expressed as mean \pm S.E.M., $n=8$ in each group.

$\mathrm{aP}<0.05$ vs. control group.

$\mathrm{bP}<0.05$ vs. HFD group.

$\mathrm{cP}<0.05$ vs. DEX + HFD group. 


\section{Figure Legends}

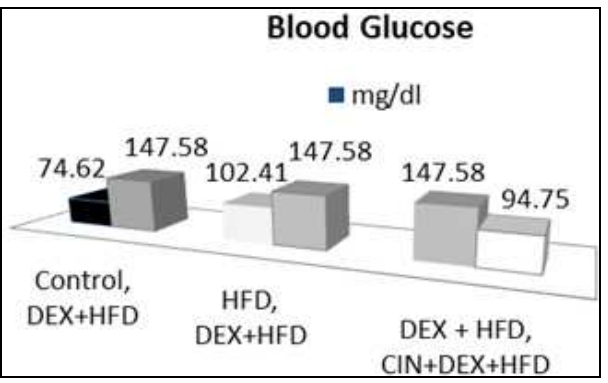

Figure 1. Blood Glucose

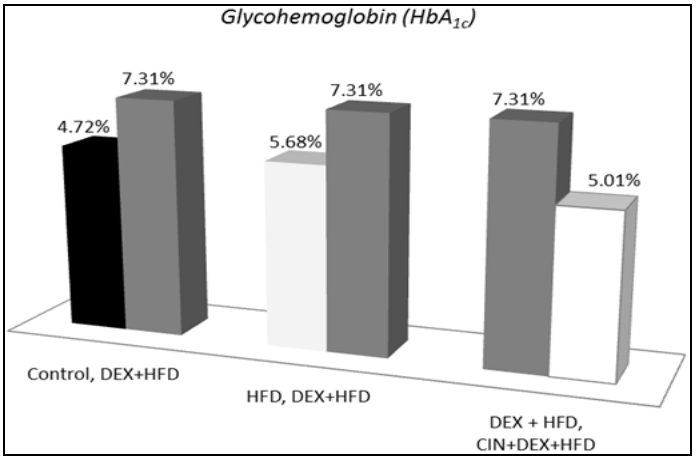

Figure 2. Glycohemoglobin (HbAlc)

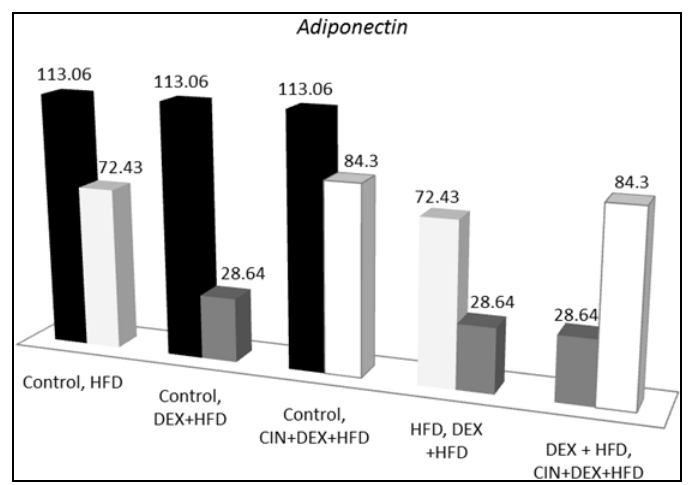

Figure 3. Adiponectin

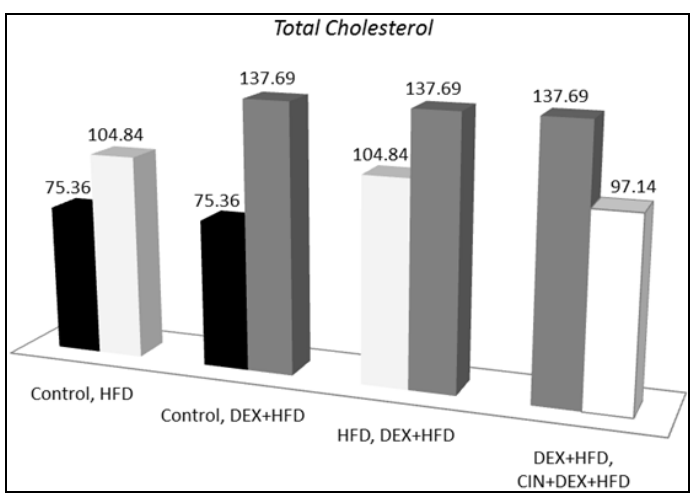

Figure 4. Total Cholesterol

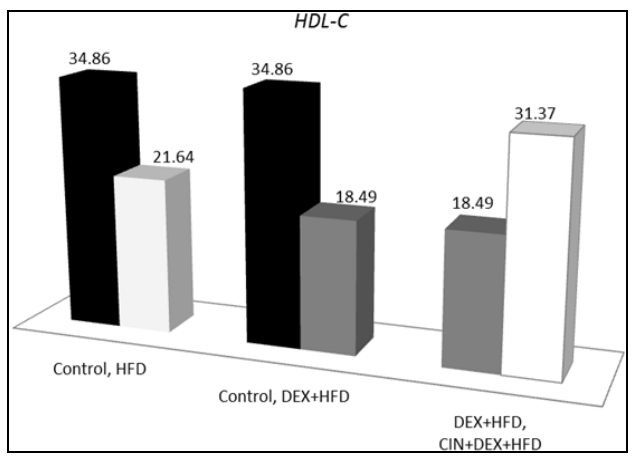

Figure 5. $H D L-C$

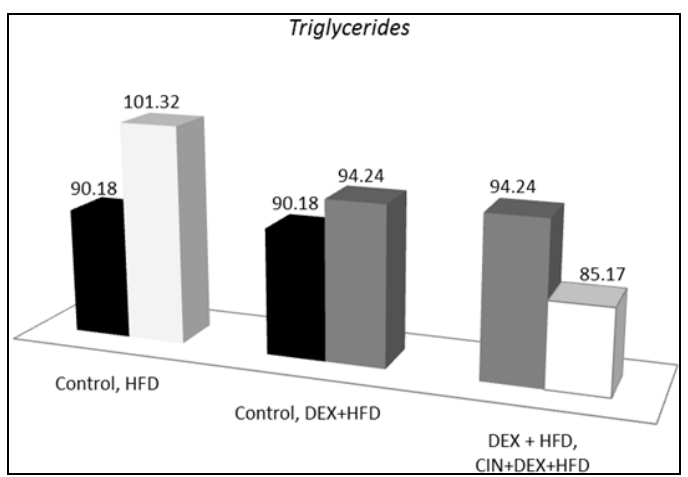

Figure 6. Triglycerides

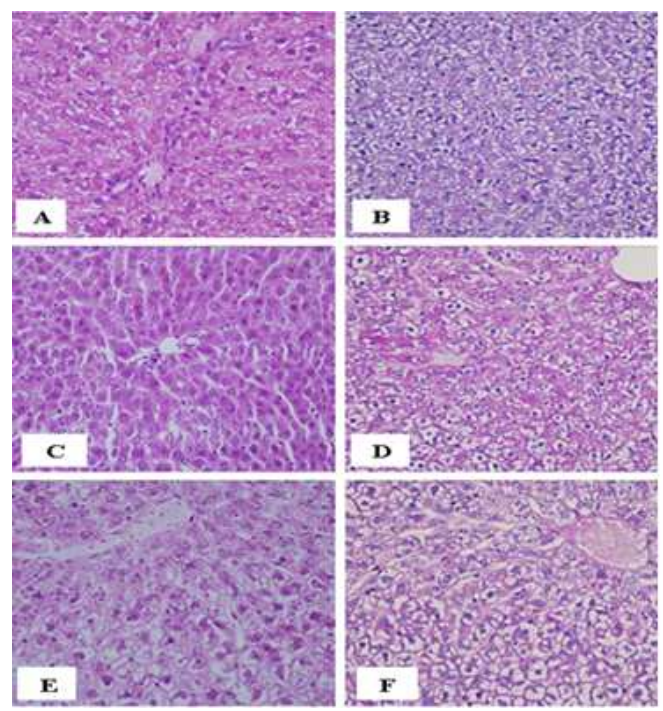

Fig 7.1. Light photomicrographs of rat liver

A and B: control group showing normal structure of the liver; [A and $\mathrm{B}, \mathrm{H} \& \mathrm{E} 400 \times]$

$[\mathrm{C}$ and $\mathrm{D}]$ rats received dexamethasone showing increased vacuolated hepatocytes; indicating increased glycogen storage $[\mathrm{C}$ and D, H\&E 200×]

$[\mathrm{E}$ and $\mathrm{F}]$ rats received dexamethasone showing iincreased vacuolated hepatocytes; indicating increased glycogen storage $[\mathrm{E}$ and F, H\&E 400×] 

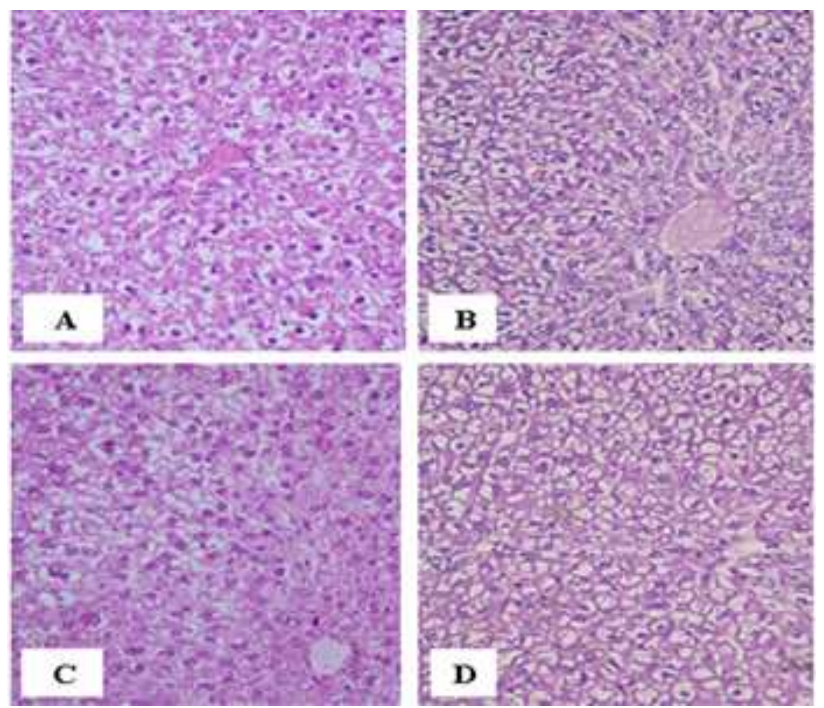

Fig 7.2. Light Photomicrographs of rat liver

- $\quad$ A and B rats received dexamethasone and high-fat diet showing increased vacuolated hepatocytes; indicating increased glycogen storage

[A and B H\&E 400× ]

$\mathrm{C}$ and $\mathrm{D}$ : rats received dexamethasone, high-fat diet and cinnamon showing decreased vacuolated hepatocytes; indicating decreased glycogen storage

[C and D, H\&E 400×]

\section{Discussion}

In the present study total cholesterol was higher, while HDL and adiponectin were lower in HFD -fed rats, as compared to control animals. However, glycosylated hemoglobin, $\mathrm{HbA1C}[\%]$ and triglycerides were not statistically different.

When cortisone was administered with HFD further increase in total cholesterol and decrease in HDL in addition to adiponectin was observed .Moreover the levels of glucose and $\mathrm{HbA} 1 \mathrm{C}[\%]$ increased significantly as compared to the control.

When cinnamon was administered for 14 days to rats receiving HFD and dexamethosone, the changed parameters went back toward normal though still higher than the control.

Furthermore in rats receiving dexamethasone and HFD, the administration of cinnamon caused decrease in size of Langerhans islets with significant decrease of vacuolization in acinar cells of the pancreas in addition to decreased glycogen storage in hepatocytes of the liver.

Several studies have demonstrated that adiponectin has a central role in glucose and lipid metabolism, the infusion of adiponectin in mice decreased the expression of hepatic gluconeogenesis enzymes, inhibited glucose production and increased the hepatic effect of insulin $[6,10]$.

In addition to its effect on glucose levels, adiponectin improved insulin sensitivity by reducing the levels of free fatty acids in the plasma and by increasing their oxidation in the muscle, according to some authors $[21,14]$.

Moreover, adiponectin has been reported to exhibit anti-atherosclerotic and anti-inflammatory effects $[17,16]$. Previous studies have shown that glucocorticoids inhibit adiponectin expression in vitro and in animal models. [9-13].

Meanwhile, cinnamon- in rats- potentiates insulin-regulated glucose utilization [3]. Cinnamon extract also significantly increases insulin sensitivity, reduces serum, and hepatic lipids, and improves hyperglycemia and hyperlipidemia possibly by regulating the PPAR-medicated glucose and lipid metabolism [19].

In patients with diabetes, cinnamon extracts have beneficial effects in reducing fasting plasma glucose, cholesterol and triglycerides [1], [20]. In overweight patients [20], [2] and women with the polycystic ovary syndrome [12], nutritional intakes of cinnamon also improve insulin sensitivity and lead to beneficial antioxidant effects.

\section{Conclusion}

Therefore the beneficial effect of cinnamon on blood glucose and $\mathrm{HbA} 1 \mathrm{C}[\%]$ observed in the present study could be due to decrease of insulin resistance secondary to the observed cinnamon induced increase in adiponectin.

The improvement in the histopathological changes after cinnamon in rats fed on high fat diet and injected with dexamethasone is confirmatory to the beneficial effect of the cinnamon.

\section{Acknowledgement}

This project was supported by the deanship of scientific research at Salman bin Abdulaziz University under the research project number $(36 / 1433 / ص)$

\section{References}

[1] Khan, M. Safdar, M.M. Ali Khan, K.N. Khattak and R.A. Anderson. Diabetes Care, 26 [2003], pp. 3215-3218. | View Record in Scopus | | Full Text via CrossRef | Cited By in Scopus [198].

[2] A.M. Roussel, I. Hininger, R. Benaraba, T.N. Ziegenfuss and R.A. Anderson. J. Am. Coll. Nutr., 28 [2009], pp. 16-21. | View Record in Scopus || Cited By in Scopus [8].

[3] Qin, M. Nagasaki, M. Ren, G. Bajotto, Y. Oshida and Y. Sato. Horm. Metab. Res., 36 [2004], pp. 119-125. | View Record in Scopus || Cited By in Scopus [61].

[4] Besse C, Nicod N, Tappy L: Changes in insulin secretion and glucose metabolism induced by dexamethasone in lean and obese females.Obes Res 2005, 13:306-311.

[5] Bullen JW Jr, Bluher S, Kelesidis T, Mantzoros CS: Regulation of adiponectin and its receptors in response to development of diet-induced obesity inmice. Am J Physiol Endocrinol Metab 2007, 292[4]:1079-1086.

[6] Combs TP, Berg AH, Obici S, Scherer PE, Rossetti L: Endogenous glucose production is inhibited by the adipose-derived protein Acrp30. J Clin Invest 2001, 108:1875-1881. 
[7] Cristiane de Oliveira, Ana BM de Mattos, Carolina Biz, Lila M Oyama, Eliane B Ribeiro, and Cláudia Maria Oller do Nascimento,High-fat diet and glucocorticoid treatment cause hyperglycemia associated with adiponectin receptor alterations;Lipids in Health and Disease 2011, Volume10,pp 10:11.

[8] Davis GF: Adverse effects of corticosteroids: II. Systemic. Clin Dermatol 1986, 4[1]:161-169.

[9] Degawa-Yamauchi M, Moss KA, Bovenkerk JE, Shankar SE, Morrison CL, Lelliott CJ, Vidal-Puig A, Jones R, Considine RV: Regulation of adiponectin expression in human adipocytes: effects of adiposity, glucocorticoids, and TNF- $\alpha$. Obes Res 2005, 13[4]:662-669.

[10] Díez JJ, Iglesias P [March 2003]. "The role of the novel adipocyte-derived hormone adiponectin in human disease". Eur. J. Endocrinol. 148 [3]: 293-300.

[11] Diez JJ, Iglesias P: The role of the novel adipocyte-derived hormone adiponectin in human disease. Eur J Endocrinol 2003, 148[3]:293-300.

[12] J.G. Wang, R.A. Anderson, G.M. Graham, M.C. Chu, M.V. Sauer, M.M. Guarnaccia and R.A. Lobo. Fertil. Steril., 88 [2007], pp. 240-243.

[13] Jang C, Inder WJ, Obeyesekere VR, Alford FP: Adiponectin, skeletal muscleadiponectin receptor expression and insulin resistance following dexamethasone. Clin Endocrinol [Oxf] 2008, 69[5]:745-750.

[14] Klöting N, Fasshauer M, Dietrich A, Kovacs P, Schön MR, Kern M, Stumvoll M, Blüher M: Insulin-sensitive obesity. Am J Physiol Endocrinol Metab 2010, 299[3]:506-515.

[15] Matsuzawa Y: Establishment of a concept of visceral fat syndrome and discovery of adiponectin. Proc Jpn Acad Ser B Phys Biol Sci 2010, 86[2]:131-141.
[16] Mousavinasab F, Tähtinen T, Jokelainen J, Koskela P, Vanhala M, Oikarinen J, Keinänen-Kiukaanniemi S: Lack of increase of serum adiponectin concentrations with a moderate weight loss during six months on a high-caloric diet in military service among a young male Finnish population. Endocrine 2005, 26[1]:65-69.

[17] Ouchi N, Kihara S, Arita Y, Nishida M, Matsuyama A, Okamoto $\mathrm{Y}$, Ishigami $\mathrm{M}$, Kuriyama $\mathrm{H}$, Kishida $\mathrm{K}$, Nishizawa H, Hotta K, Muraguchi M, Ohmoto Y,Yamashita S, Funahashi T, Matsuzawa Y: Adipocyte-derived plasma protein, adiponectin, suppresses lipid accumulation and classAscavenger receptor expression inhuman monocyte-derived macrophages. Circulation 2001, 103:1057-1063

[18] Plasma adiponectin concentrations in children: relationships with obesity and insulinemia. J Clin Endocrinol Metab 2001, 87[10]:4652-4656.

[19] Stefan N, Bunt JC, Salbe AD, Funahashi T, Matsuzawa Y, Tataranni PA: Sung Hee Kim, Se Young Choung Antihyperglycemic and antihyperlipidemic action of Cinnamomi Cassiae [Cinnamon bark] extract in C57BL/Ks $\mathrm{db} / \mathrm{db}$ mice Archives of Pharmacal Research February 2010, Volume 33, Issue 2, pp 325-333.

[20] T.N. Ziegenfuss, J.E. Hofheins, R.W. Mendel, J. Landis and R.A. Anderson. J. Int. Soc. Sports Nutr., 3 [2006], pp. 45-53. | View Record in Scopus || Full Text via CrossRef | Cited By in Scopus [26].

[21] Yamauchi T, Kamon J, Minokoshi Y, Ito Y, Waki H, Uchida S, Yamashita S,Noda M, Kita S, Ueki K, Eto K, Akanuma Y, Froguel P, Foufelle F, Ferre P,Carling D, Kimura S, Nagai R, Kahn BB, Kadowaki T: Adiponectin stimulates glucose utilization and fatty-acid oxidation by activating AMP-activated protein kinase. Nat Med 2002, 8:1288-1295. 